\title{
Photochemical Behavior of Some $p$-Styrylstilbenes and Related Compounds: Spectral Properties and Photoisomerization in Solution and in Solid-state
}

Zhu Fengqiang, Jiro Motoyoshiya, ${ }^{*}$ Junji Nakamura, Yoshinori Nishii, Hiromu Aoyama

Department of Chemistry, Faculty of Textile Science, Shinshu University, Ueda, Nagano 386-8567, Japan

\author{
Phone: +81 268215402 \\ Fax: +81268215391 \\ e-mail: jmotoyo@shinshu-u.ac.jp
}

Keywords: Photoisomerization, Solid-state, Styrylstilbene, Distyrylstilbene, Absorption spectrum, Fluorescence spectrum 


\section{ABSTRACT}

The spectral properties and Z,E-photoisomerizations of three 4-styrylstilbenes, a 4,4'-bis( $\beta$-methylstyryl)benzene, and a 4,4'-distyrylstilbene were investigated in solution and in the solid-state. Some notable features of the absorption and fluorescence spectra due to the structures and the phases (solution or solid) were observed especially the Stokes shifts. Interesting photochemical behaviors in solution and in the solid-state were also found. While the (E,Z)-4-styrylstilbenes undergo a one-way photoisomerization to their E,E-isomers with almost equal rates in solution, their quantum yields in the solid-state decrease with increasing substituent size at the terminal aromatic rings. On the other hand, the 4,4 '-bis( $\beta$-methylstyryl)benzene undergoes a mutual photoisomerization in solution, but its E,Z-isomer isomerizes in a one-way manner to the E,E-isomer in the solid-state. Additionally, the (Z,E,Z)- 4,4'-styrylstilbene was found to undergo a one-way photoisomerization to the $E, E, E$-isomer via the $E, E, Z$-isomer in solution and the crystalline $E, E, Z$-isomer to the $E, E, E$-isomer in the solid-state. 


\section{INTRODUCTION}

Poly- and oligo(phenylene vinylene)s are compounds with extended conjugated $\pi$-systems and that have received much attention because of their electrooptic properties (1-6). Most oligo(phenylene vinylene)s are strongly fluorescent and various kinds of their variants have been synthesized $(7,8)$. Among the various oligo(phenylene vinylene)s, the 4-styrylstilbenes are the simplest derivatives with a strong fluorescence and have been frequently used as emitters $(9,10)$. As examples of their modifications, several 4-styrylbenzenes with various substituents were used as fluorophores during chemiluminescence reactions (11-13), and a photoinduced energy transfer of a fullerene-(4-styrylstilbene) conjugate was investigated (14). However, only a few investigations have been documented in regard to the photochemical behavior of the 4-styrylstilbenes. For example, their geometrical isomers are known to undergo a one-way photoisomerization to all-E-isomers (15-17), but their photoreaction in the solid-state has not yet been investigated. Considering recent development of solid-state photochemistry (18-21) and from the viewpoint of the utilization of these types of compounds as electronic materials, it is important to explore their photochemical behaviors in the solid-state. In this paper, we describe the spectral properties and $Z$,E-photoisomerization of some 4-styrylstilbenes and a 4,4'-distyrylstilbene, both in solution and in the solid-state.

\section{MATERIAL AND METHODS}

General remarks: Melting points were determined on a hot stage microscope apparatus (Mitamura). ${ }^{1} \mathrm{H}$ and ${ }^{13} \mathrm{C}$ NMR spectra were recorded on a Bruker AVANCE-400 at $400 \mathrm{MHz}$ and $100 \mathrm{MHz}$ respectively. The chemical shifts $(\delta)$ are reported in ppm downfield from TMS as internal standard or from the residual solvent peak. Coupling constants $(J)$ are reported in Hz. Low resolution mass spectra (MS) were recorded with the use of the JOEL JMS-K9 spectrometers. Elemental analyses were performed on a Perkin-Elmer $2400 \mathrm{CHN}$ elemental analyzer. Analytical TLC was carried out on precoated silica gel 60F-254 plates (E. Merck). Column chromatography was performed on silica gel (E. Merck). Absorption and fluorescence spectra were recorded on a U-3310 spectrometer (Hitachi) and on a RF-5000 spectrometer (Shimadzu), respectively. Fluorescence quantum yields were estimated using 9,10-diphenylanthracene $\left(\Phi_{\mathrm{F}}=0.91\right.$ in benzene) as a standard.

Preparation of (E,E)- and (E,Z)-4-Styrylstilbene (1a). A mixture of p-xylene-bis(phosphonium chloride) (6.80 g, $9.73 \mathrm{mmol})$ and benzaldehyde (1.00 g, $9.80 \mathrm{mmol})$ were dissolved in a mixed 
solvent of DMF (dimethylformamide) $(30 \mathrm{~mL})$ and ethanol $(20 \mathrm{~mL})$ at $-5^{\circ} \mathrm{C}$ under a nitrogen atmosphere. Lithium ethoxide $(2.0 \mathrm{~g}, 38.5 \mathrm{mmol})$ dissolved in ethanol (50 mL) was added slowly to the mixture and the resulting solution was stirred for $6 \mathrm{~h}$ at $-5{ }^{\circ} \mathrm{C}$. After removal of the solvent under a reduced pressure, a saturated ammonium chloride solution and benzene were added to the residue. The insoluble substance was filtered off to afford a green solid of $(E, E)-1 a(0.15 \mathrm{~g}, 11 \%)$. The organic extract was washed with water and dried over anhydrous $\mathrm{Na}_{2} \mathrm{SO}_{4}$, and removal of the solvent gave the crude products containing $(E, Z)-$ and $(Z, Z)-\mathbf{1 a}$. The products were treated with petroleum ether, and the insoluble component was $(E, Z)-\mathbf{1 a}$, which was recrystallized from methanol to afford white crystals $(0.18 \mathrm{~g}, 14 \%)$. Pure $(Z, Z)-1$ a could nit be separated from the mixture. (E,E)-1a: $\mathrm{mp} 261-262{ }^{\circ} \mathrm{C}$ (Lit.: 263-264 ${ }^{\circ} \mathrm{C}$ ) (22); UV/Vis (benzene) $\lambda_{\max }(\log \varepsilon) 356$ (4.7) nm; Fluorescence (benzene) $\lambda_{\max }\left(\Phi_{\mathrm{F}}\right) 411(0.99) \mathrm{nm} ;{ }^{1} \mathrm{H}$ NMR $\delta 7.10$ (d, 2H, $\left.J=16 \mathrm{~Hz}\right), 7.14$ (d, 2H, $J=16 \mathrm{~Hz}), 7.24-7.28(\mathrm{~m}, 8 \mathrm{H}), 7.35-7.38$ (t, 2H, $J=7.8 \mathrm{~Hz}), 7.49-7.54$ (t, 4H, $J=8.0 \mathrm{~Hz})$; (E,Z)-1a: mp 122-123 ${ }^{\circ} \mathrm{C}$ (Lit.: $121-122{ }^{\circ} \mathrm{C}$ ) (20); UV/Vis (benzene) $\lambda_{\max }(\log \varepsilon) 339(4.5) \mathrm{nm} ;{ }^{1} \mathrm{H}$ NMR $\delta 6.57(\mathrm{~d}, 1 \mathrm{H}, J=12 \mathrm{~Hz}), 6.61(\mathrm{~d}, 1 \mathrm{H}, J=12 \mathrm{~Hz}), 7.05(\mathrm{~d}, 1 \mathrm{H}, J=16 \mathrm{~Hz}), 7.09$ (d, 1H, $J=16$ $\mathrm{Hz}), 7.20-7.30(\mathrm{~m}, 8 \mathrm{H}), 7.33-7.38(\mathrm{~m}, 4 \mathrm{H}), 7.48-7.51(\mathrm{t}, 2 \mathrm{H}, J=7.6 \mathrm{~Hz})$.

Preparation of (E,E)-, (E,Z)-and (Z,Z)-4-Methyl-4'-(4”-methylstyryl)stilbene (1b). Prepared similarly to the above procedure with the use of $p$-xylene-bis(phosphonium chloride) (7.00 g, 10.0 mmol $)$, 4-methylbenzaldehyde $(2.00 \mathrm{~g}, 16.7 \mathrm{mmol})$ and lithium ethoxide $(2.3 \mathrm{~g}, 44.2 \mathrm{mmol})$. The product was treated with petroleum ether, and $(E, E)-\mathbf{1 b}$ was obtained as a precipitate, which was recrystallized from benzene/hexane to afford green crystals $(0.26 \mathrm{~g}, 10 \%)$. From the petroleum ether-soluble components (E,Z)-1b was obtained as an ether-insoluble substance, which was recrystallized from methanol $(0.44 \mathrm{~g}, 17 \%)$. Concentration of the ether solution obtained after removal of $(E, Z)-\mathbf{1 b}$ gave $(Z, Z)-\mathbf{1 b}$, which was recrystallized from methanol to afford light green crystals of (Z,Z)-1b (0.82 g, 32\%). (E,E)-1b: UV/Vis (benzene) $\lambda_{\max }(\log \varepsilon) 361$ (4.52) nm, (solid) $398 \mathrm{~nm}$; Fluorescence (benzene) $\lambda_{\max }\left(\Phi_{\mathrm{F}}\right) 396,419(0.99) \mathrm{nm} ;{ }^{1} \mathrm{H}$ NMR $\delta 2.36(\mathrm{~s}, 6 \mathrm{H}), 7.05(\mathrm{~d}, 2 \mathrm{H}$, $J=16 \mathrm{~Hz}), 7.10$ (d, 2H, $J=16 \mathrm{~Hz}), 7.17$ (d, 4H, $J=8 \mathrm{~Hz}), 7.42$ (d, 4H, $J=8 \mathrm{~Hz}), 7.49$ (s, 4H); mp 197-198 ${ }^{\circ} \mathrm{C}$ (lit: $198-200{ }^{\circ} \mathrm{C}$ ) (23); (E,Z)-1b: mp 148-150 ${ }^{\circ} \mathrm{C}$; UV/Vis (benzene) $\lambda_{\max }(\log \varepsilon) 340$ (4.48) nm, (solid) $373 \mathrm{~nm} ;{ }^{1} \mathrm{H}$ NMR $\delta 2.32$ (s, 3H), 2.35 (s, 3H), 6.52 (d, 1H, J=12 Hz), 6.57 (d, 1H, $J=12 \mathrm{~Hz}), 7.00(\mathrm{~d}, 1 \mathrm{H}, J=16 \mathrm{~Hz}), 7.04(\mathrm{~s}, 2 \mathrm{H}), 7.07$ (d, 1H, $J=16 \mathrm{~Hz}), 7.14-7.40(\mathrm{~m}, 10 \mathrm{H}) ;{ }^{13} \mathrm{C}$ NMR $\oint 21.631126 .58,126.79,127.79,128.83,129.17,129.35,129.61,129.78,130.62,134.80$, 135.00, 136.62, 137.03, 137.31, 137.88 . MS (m/z) $310\left(\mathrm{M}^{+}\right)$. Anal. Calcd for $\mathrm{C}_{24} \mathrm{H}_{22}: \mathrm{C}$, 92.86; H, 7.14. Found: C, 92.94; H, 7.27. (Z,Z)-1b: mp 82-83 ${ }^{\circ} \mathrm{C}$; UV/Vis (benzene) $\lambda_{\max }(\log \varepsilon)$ $330(4.24) \mathrm{nm}$, (solid) $400 \mathrm{~nm} ;{ }^{1} \mathrm{H}$ NMR $\$ 2.31$ (s, 6H), 6.49 (d, 2H, J=12 Hz), 6.54 (d, 2H, J= 12 
$\mathrm{Hz}), 7.02(\mathrm{~d}, 4 \mathrm{H}, J=8 \mathrm{~Hz}), 7.12(\mathrm{~s}, 4 \mathrm{H}), 7.15(\mathrm{~d}, 4 \mathrm{H}, J=8 \mathrm{~Hz}) ;{ }^{13} \mathrm{C} \mathrm{NMR} \delta \tilde{1} .1$.

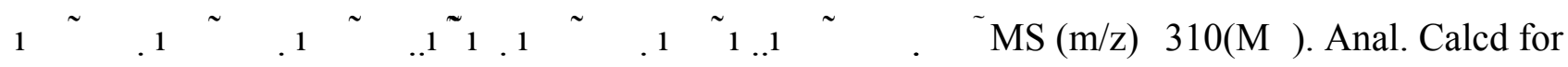
$\mathrm{C}_{24} \mathrm{H}_{22}$ : C, 92.86; H, 7.14\%. Found: C, 93.16; H, 7.31\%.

Preparation of (E,E)- and (E,Z)-4-tert-butyl-4'-(4"-tert-butylstyryl)stilbene (1c). Prepared using the above procedure from $p$-xylene-bis(phosphonium chloride) $(5.00 \mathrm{~g}, 7.15 \mathrm{mmol})$, 4-tert-butylbenzaldehyde (1.70 g, $10.5 \mathrm{mmol})$, and lithium ethoxide (1.60 g, $30.8 \mathrm{mmol})$. The product was treated with petroleum ether, and $(E, E)-\mathbf{1 c}$ was obtained as the petroleum ether-insoluble substance, which was recrystallized from benzene/hexane to afford light green crystals $(0.22 \mathrm{~g}, 11 \%)$. From the petroleum ether-soluble components, $(E, Z)-1 \mathrm{c}$ was obtained as the methanol-insoluble substance, which was recrystallized from methanol to afford white crystals (0.28 g, 14\%). Pure (Z,Z)-1c was unsuccessfully obtained. (E,E)-1c: mp 100-102 ${ }^{\circ} \mathrm{C}$; UV/Vis (benzene) $\lambda_{\max }(\log \varepsilon) 362(4.46) \mathrm{nm}$, (solid) $419 \mathrm{~nm} ;{ }^{1} \mathrm{H}$ NMR $\delta 1.34$ (s, 18H), 7.06 (d, 2H, $J=16$ Hz), 7.12 (d, 2H, $J=16 \mathrm{~Hz}), 7.39$ (d, 4H, $J=8 \mathrm{~Hz}), 7.46(\mathrm{~d}, 4 \mathrm{H}, J=8 \mathrm{~Hz}), 7.49$ (s, 4H); mp 149-151 ${ }^{\circ} \mathrm{C}$ (lit: $\left.151-153{ }^{\circ} \mathrm{C}\right)(24)$; (E,Z)-1c: UV/Vis (benzene) $\lambda_{\max }(\log \varepsilon) 343$ (4.42) nm, (solid) $418 \mathrm{~nm} ;{ }^{1} \mathrm{H}$ NMR $\delta 1.31$ (s, 9H), 1.33 (s, 9H), 6.53 (d, 1H, J=12 Hz), 6.56 (d, 1H, J=12 Hz), 7.03 $(\mathrm{d}, 1 \mathrm{H}, J=16 \mathrm{~Hz}), 7.06(\mathrm{~s}, 2 \mathrm{H}), 7.09(\mathrm{~d}, 1 \mathrm{H}, J=16 \mathrm{~Hz}), 7.16-7.49(\mathrm{~m}, 10 \mathrm{H}) ;{ }^{13} \mathrm{C} \mathrm{NMR} \delta 31.09$, 34.39.,126.17, 126.38, 127.38, 128.42, 128.76, 128.96, 129.20, 129.37, 130.21, 134.39, 134.59, 136.21, 136.63, 137.01, 137.47; EI-MS (m/z) 394(M $\left.{ }^{+}\right)$. Anal. Calcd for $\mathrm{C}_{30} \mathrm{H}_{34}$ : C, 91.32; H, 8.68. Found: C, 91.54; H, 8.52.

Preparation of (E,E)-1,4-Bis(4'-methyl- $\beta$-methylstyryl)benzene (2). A mixture of 4-methylacetophenone (1.00 g, $7.46 \mathrm{mmol})$ and 1,4-bis(dimethylphosphonomethyl)benzene (1.40 g, $4.35 \mathrm{mmol}$ ), prepared from the reaction of 1,4-bis(chloromethyl)benzene with trimethyl phosphite in DMF (40 ml), were dissolved in DMF $(30 \mathrm{ml})$, and to this solution potassium tert-butoxide (1.90 $\mathrm{g}, 17.0 \mathrm{mmol}$ ) was added at room temperature. After being stirred for $10 \mathrm{~h}$ under a nitrogen atmosphere and removal of the solvent under a reduced pressure, ammonium chloride solution was added to the residue and the product was extracted with chloroform. Drying over anhydrous $\mathrm{Na}_{2} \mathrm{SO}_{4}$ and removal of the solvent gave the crude product, which was purified by column chromatography to afford (E,E)-2. Recrystallization from methanol afforded light yellow crystals $(0.26 \mathrm{~g}, 21 \%)$. (E,E)-2: mp 182-184 ${ }^{\circ} \mathrm{C}$; UV/Vis (benzene) $\lambda_{\max }(\log \varepsilon) 318$ (4.55) nm, (solid) 379 nm; Fluorescence (benzene) $\lambda_{\max }\left(\Phi_{\mathrm{F}}\right) 448(0.19) \mathrm{nm}{ }^{1} \mathrm{H}$ NMR $\delta 2.31(\mathrm{~d}, 6 \mathrm{H}, J=1.2 \mathrm{~Hz}), 2.37(\mathrm{~s}, 6 \mathrm{H})$, $6.82(\mathrm{~s}, 2 \mathrm{H}), 7.18(\mathrm{~d}, 4 \mathrm{H}, J=8.0 \mathrm{~Hz}), 7.37(\mathrm{~s}, 4 \mathrm{H}), 7.43(\mathrm{~d}, 4 \mathrm{H}, J=8.4 \mathrm{~Hz}) ;{ }^{13} \mathrm{C} \mathrm{NMR} \delta 18.03$, 21.48, 126.26, 127.20, 129.37, 129.42, 136.96, 137.32, 137.63, 141.61. MS (m/z): 338( $\left.\mathrm{M}^{+}\right)$. Anal. 
Calcd for $\mathrm{C}_{26} \mathrm{H}_{26}: \mathrm{C}, 92.26 ; \mathrm{H}, 7.74 \%$. Found: C, 92.06; H, 7.95\%.

Preparation of (E,Z)-1,4-Bis(4'-methyl- $\beta$-methylstyryl)benzene (2). A solution of a mixture of (E,E)-2 ( $0.20 \mathrm{~g}, 0.59 \mathrm{mmol})$ in benzene was irradiated under the conditions described bellow to give a photostationary mixture. After removal of benzene, the crystalline residue containing $(E, E)$ and $(E, Z)-2$ in 37:63 ratio was treated with methanol. The precipitated $(E, E)-2$ was filtered off and concentration of the filtrate gave crude $(E, Z)-2$, which was recrystallized from methanol to afford white crystals $(0.10 \mathrm{~g}, 50 \%)$. (E,Z)-2: $\mathrm{mp} 65-67{ }^{\circ} \mathrm{C}$; UV/Vis (benzene) $\lambda_{\max }(\log \varepsilon) 318(4.49) \mathrm{nm}$, (solid) $371 \mathrm{~nm} ;{ }^{1} \mathrm{H}$ NMR $\delta 2.19$ (d, 3H, $\left.J=1.2 \mathrm{~Hz}\right), 2.23$ (d, 3H, $\left.J=1.2 \mathrm{~Hz}\right), 2.34$ (s, 6H), 6.44 (s, 1H), 6.69 (s, 1H), 6.96 (d, 2H, $J=8.0 \mathrm{~Hz}), 7.11-7.15(\mathrm{~m}, 8 \mathrm{H}),$,7.37 (d, 2H, $J=8.4 \mathrm{~Hz}) ;{ }^{13} \mathrm{C} \mathrm{NMR}$ $\oint 18.04,21.46,21.63,27.70,126.23,126.45,127.29,128.44,129.07,129.09,129.37,129.61$, 136.28, 136.54, 136.99, 137.20, 137.25, 139.04, 139.56, 141.73 . MS (m/z): 338( $\left.{ }^{+}\right)$. Anal. Calcd for $\mathrm{C}_{26} \mathrm{H}_{26}$ : C, 92.26; $\mathrm{H}, 7.74 \%$. Found: $\mathrm{C}, 92.24 ; \mathrm{H}, 8.02 \%$.

Preparation of (E,E,E)-, (E,E,Z)- and (Z,E,Z)-4,4'-Bis[4"'-p-2-ethylhexyloxystyryl]stilbene (3). The two-fold Wittig reaction using (E,E)-4,4'-bis(bromotriphenylphosphoranylmethyl)stilbene (3.0 g, $3.30 \mathrm{mmol}$ ) prepared by a three step synthesis starting from 4-methylbenzaldehyde, 4-(2-ethylhexyloxy)benzaldehyde $(1.40 \mathrm{~g}, 5.98 \mathrm{mmol})$ prepared from 4-hydroxybenzaldehyde and 2-ethylhexylbromide, and lithium ethoxide $(0.90 \mathrm{~g}, 17.3 \mathrm{mmol})$ was carried out in a similar manner to that described for 1a. A mixture of the crude products was treated with benzene, and the benzene-insoluble pale green powder was analytically pure (E,E,E)-3 $(0.34 \mathrm{~g}, 18 \%)$. The solution obtained after filtration was concentrated and the residue was subjected to silica gel column chromatography using benzene as eluant to afford a mixture of $(E, E, Z)$ - and $(Z, E, Z)-3$, which was treated with hexane. The hexane-insoluble substance was filtered off and recrystallized from hexane to afford green crystals of $(E, E, Z)-3(0.45 \mathrm{~g}, 23 \%)$. The hexane solution after removal of (E,E,Z)-3 was concentrated to give a light-green oil of $(Z, E, Z)-3 \quad(0.71 \mathrm{~g}, 36 \%)$. $(E, E, E)-3: \mathrm{mp}>300{ }^{\circ} \mathrm{C} ; \mathrm{UV}$ (benzene) $\lambda_{\max }(\log \varepsilon) 395(4.93) \mathrm{nm}$, (solid) $470 \mathrm{~nm}$; Fluorescence (benzene) $\lambda_{\max }\left(\Phi_{\mathrm{F}}\right) 436,462$ $(0.98) \mathrm{nm} ;{ }^{1} \mathrm{H}$ NMR $\delta$ 0.91-1.75 (m, 30H), $3.86(\mathrm{~d}, 4 \mathrm{H}, J=6.0 \mathrm{~Hz}), 6.90(\mathrm{~d}, 4 \mathrm{H}$, aromatic, $J=9.2$ $\mathrm{Hz}), 6.97(\mathrm{~d}, 2 \mathrm{H}, J=16 \mathrm{~Hz}), 7.09$ (d, 2H, $J=16 \mathrm{~Hz}), 7.11$ (s, 2H, aromatic), 7.45 (d, 4H, aromatic, $J$ $=8.4 \mathrm{~Hz}), 7.46-7.51\left(\mathrm{~m}, 8 \mathrm{H}\right.$, aromatic); $\quad{ }^{\mathrm{MS}}(\mathrm{m} / \mathrm{z})$ 640(M+). (E,E,Z)-3: $\mathrm{mp} 151-153{ }^{\circ} \mathrm{C} ; \mathrm{UV}$ (benzene) $\lambda_{\max }(\log \varepsilon) 385(4.58) \mathrm{nm}$, (solid) $445 \mathrm{~nm} ;{ }^{1} \mathrm{H}$ NMR $\delta 0.91-1.75$ (m, 30H), $3.82(\mathrm{~d}, 2 \mathrm{H}, J$ $=6.8 \mathrm{~Hz}), 3.86(\mathrm{~d}, 2 \mathrm{H}, J=6.0 \mathrm{~Hz}), 6.47(\mathrm{~d}, 1 \mathrm{H}, J=12 \mathrm{~Hz}), 6.53(\mathrm{~d}, 1 \mathrm{H}, J=12 \mathrm{~Hz}), 6.77(\mathrm{~d}, 2 \mathrm{H}, J$ $=7.2 \mathrm{~Hz}), 6.89(\mathrm{~d}, 2 \mathrm{H}, J=9.2 \mathrm{~Hz}), 6.96(\mathrm{~d}, 1 \mathrm{H}, J=16 \mathrm{~Hz}), 7.07(\mathrm{~s}, 2 \mathrm{H}), 7.08$ (d, 1H, J=16Hz), 7.21 $(\mathrm{d}, 2 \mathrm{H}, J=8.4 \mathrm{~Hz}), 7.28(\mathrm{~d}, 2 \mathrm{H}, J=8.4 \mathrm{~Hz}), 7.38(\mathrm{~d}, 2 \mathrm{H}, J=8.4 \mathrm{~Hz}), 7.44(\mathrm{~d}, 2 \mathrm{H}, J=8.8 \mathrm{~Hz}), 7.47$ 
(s, 4H); ${ }^{13} \mathrm{C}$ NMR $\delta 11.50,14.46,23.43,24.26,29.48,30.92,39.79,71.01,114.62,115.17,118.35$, 126.37, 126.68, 126.92, 127.17, 128.06, 128.66, 129.60, 130.48; $\quad$ MS (m/z) $640\left(\mathrm{M}^{+}\right) .(Z, E, Z)-3$ : UV (benzene) $\lambda_{\max }(\log \varepsilon) 369(4.31) \mathrm{nm} ;{ }^{1} \mathrm{H}$ NMR $\oint 0.87-1.72(\mathrm{~m}, 30 \mathrm{H}), 3.82(\mathrm{~d}, 4 \mathrm{H}, J=5.6 \mathrm{~Hz})$, $6.46(\mathrm{~d}, 2 \mathrm{H}, J=12 \mathrm{~Hz}), 6.52(\mathrm{~d}, 2 \mathrm{H}, J=12 \mathrm{~Hz}), 6.76(\mathrm{~d}, 4 \mathrm{H}, J=8.8 \mathrm{~Hz}), 7.03(\mathrm{~s}, 2 \mathrm{H}), 7.20(\mathrm{~d}, 4 \mathrm{H}$, $J=8.8 \mathrm{~Hz}), 7.27(\mathrm{~d}, 4 \mathrm{H}, J=8.4 \mathrm{~Hz}), 7.36(\mathrm{~d}, 4 \mathrm{H}, J=8.4 \mathrm{~Hz}) ;{ }^{13} \mathrm{C} \mathrm{NMR} \delta 11.51,14.47,23.4424 .27$, 29.50, 30.94, 39.80, 70.90, 114.64, 126.69, 128.53, 129.59, 129.84, 130.42, 130.49, 136.36, 137.43, 159.03; EI-MS (m/z) 640(M+).

Irradiation of 1a in solution. A typical procedure. A $25 \mathrm{~mL}$ solution of $1 \mathrm{a}\left(1 \times 10^{-3} \mathrm{M}\right)$ in distilled benzene in a Pyrex glass-tube was bubbled with nitrogen gas for $30 \mathrm{~min}$ and the tube was sealed with a three-way stopcock. The glass-tube was irradiated with a $500 \mathrm{~W}$ high-pressure mercury lamp $(\lambda>300 \mathrm{~nm})$. Aliquots were removed at ten minutes intervals under a nitrogen stream. The solvent was removed and the residues were dissolved in deuterated chloroform. Isomers ratios were determined by ${ }^{1} \mathrm{H}$ NMR analyses.

In a similar manner to that described above, the photoreactions of all other compounds in solution were carried out in the same geometry.

Irradiation of $1 \mathbf{a}$ in the solid-state. A typical procedure. Powder of $1 \mathbf{a}(30 \mathrm{mg})$ was placed in a 30 $\mathrm{ml}$ Pyrex-flask and degassed under vacuum. The flask was cooled at $-72{ }^{\circ} \mathrm{C}$ and the sample was irradiated with a $500 \mathrm{~W}$ high-pressure mercury lamp through a band-pass filter (HA 50) that passes only light in the 300-400 nm range. After irradiation for the stated hours, the powder was dissolved in deuterated chloroform and its ${ }^{1} \mathrm{H}$ NMR spectrum was recorded.

This procedure was applied to the solid-state photoisomerization of all other compounds.

\section{RESULTS AND DISCUSSION}

\section{Spectral properties of styrylstilbenes and distyrylstilbene}

The 4-styrylstilbenes (1a-c), bis( $\beta$-methylstyryl)benzene (2), and 4,4'-distyrylstilbene (3) were prepared by the Wittig reaction or the related olefination reaction using the corresponding phosphoniumylides or the phosphonates and the aromatic aldehydes, from which almost all of the geometrical isomers of the molecules shown in Fig. 1 were isolated.

\section{$\underline{\text { Figure } 1}$}

Representative spectra of $\mathbf{1 b}, \mathbf{2}$, and $\mathbf{3}$ are shown in Fig. 2 and Fig. 3.

\section{Figure 2 and Figure 3}

As shown in Fig. 2a, all geometrical isomers of $\mathbf{1 b}$ show weakly structured absorption spectra from 
300-400 nm and a structured emission spectrum from 450-500 nm, in which the absorption spectra coincided with the excitation spectra and there was no effect of concentration and excitation wavelengths on the fluorescence spectra. In comparison with $(E, E)-1 \mathbf{a}-\mathbf{c}$, their $E, Z$ - and Z,Z-isomers underwent a blue shift in the absorption spectra but gave almost same fluorescence spectra except for its intensity. These spectral properties are identical with those of 3,3",5,5"'-tetra-tert-butyl-4'-styrylstilbenes whose fluorescence is composite as a result of adiabatic isomerization processes (16). Compound 2 underwent a significant blue shift in the absorption spectrum, whereas it has longer wavelength emission bands than compound 1 (Fig. 3a). A possibility that the emission of $\mathbf{2}$ arises from an excimer is ruled out because dilution of solution to one-tenth concentration had no effect on the fluorescence spectra. The observed small fluorescence quantum yields and the large Stokes shift of $2\left(9100 \mathrm{~cm}^{-1}\right.$ for E,E-2 and $9000 \mathrm{~cm}^{-1}$ for E,Z-2) are probably due to its twisted structure in the ground state that might cause a significant structural difference in the singlet excited state, namely, the excited state generated by light absorption will take a much more planar geometry than the ground state. As expected from the additional conjugated styryl group, 3 exhibits both absorption and emission at longer wavelength regions probably (Fig. 3b). Also in the fluorescence spectra of 3, the same behavior to that described in the p-styrylstilbenes has been observed.

Of significance is a comparison of the spectra measured in the solid-state with those in solution. Pronounced red shifts in the solid-state absorption and fluorescence spectra were observed for $\mathbf{1 b}$ (Fig. 2b). In addition, it is worthy to note that in contrast to the solution spectra, the fluorescence spectra of the isomers in the solid-state are different. Observation of the original emission from each isomer indicates that intermolecular interactions between the planner molecules of $(E, E)-\mathbf{1 b}$ prevent adiabatic photoisomerization. It is also interesting to refer to the much smaller Stokes shift of $(Z, Z)-1 \mathbf{b} \quad\left(3200 \quad \mathrm{~cm}^{-1}\right)$ in the solid-state compared to that of $(Z, Z)-3,3$ ",5,5"-tetra-tert-butyl-4'styrylbenzenes $\left(8000 \mathrm{~cm}^{-1}\right)$ measured at $153 \mathrm{~K}$ in methylcyclohexane, which would be ascribed to the confined environment in the solid-state that inhibits a large structural change between the ground and the excited states. On the other hand, 2 shows no appreciable difference in the spectra measured in solution and in the solid-state probably because of its twisted structure that would prevent any interaction with other molecules even in the solid-state.

\section{Photoisomerization in solution and in the solid-state}

Upon irradiation in benzene all the $(E, Z)-\mathbf{1 a}-\mathbf{c}$ isomers underwent one-way photoisomerization to give their E,E-isomers, where no significant difference in the rates was found (Fig. 4a). In contrast, solid-state photoisomerization is sensitive to the terminal substituents (Fig. 4b). When powders of 
pure $(E, Z)$-1a-c were irradiated, the solid-state photoisomerization also proceeded in a one-way manner to their $E, E$-isomers with diminishing quantum yields with increasing substituent size.

\section{Figure 4}

Therefore, the movement of the terminal aromatic groups in the confined environment is controlled by the bulkiness of the $p$-substituent. A structural effect on the crystalline-state photoisomerization rates has been recently reported in 1,6-diphenylhexa-1,3,5-triene 4,4'-dicarboxylic acid dialkyl esters, in which the long alkyl chain in the terminal ester moiety enhanced the photoreactivity because of the increase in the conformational flexibility (25). Our results obtained for 1a-c are in contrast to the above systems probably due to differences in crystal lattice interaction.

When (Z,Z)-1b was irradiated in benzene under the same conditions, it changed into the $E$,E-isomer but a small amount of the $E, Z$-isomer was detected as revealed by monitoring the ${ }^{1} \mathrm{H}$ NMR spectrum (Fig. 5a). In spite of the mere formation of the E,Z-isomer as a presumable precursor to the E,E-isomer, $(Z, Z)-\mathbf{1 b}$ underwent a one-way photoisomerization by two-fold adiabatic processes in a singlet manifold in the same manner to the photoisomerization of (Z,Z)-3,3",5,5"-tetra-tert-butyl-4'-styrylstilbene (16).

\section{Figure 5}

In contrast, during the solid-state photoisomerization of $(Z, Z)-\mathbf{1 b}$, the E,Z-isomer could not be detected and only the E,E-isomer was traced as the product (Fig. 5b), resulting in a seemingly unimolecular process. An interesting pathway, a one-step transformation called the bicycle-pedal mechanism $(21,26)$ proposed for the photoisomerization of the conjugated polyenes such as retinal, might be applied to this solid-state photoisomerization if regarding the central benzene ring of the styrylstilbenes as an ethylene unit. As shown in Fig. 2b, the solid-state fluorescence spectrum of $(E, E)-\mathbf{1 b}$ formed by the photoisomerization of $(Z, Z)-\mathbf{1 b}$ was coincident with that of the independently prepared $(E, E)-\mathbf{1 b}$. Tracing the photochemical change of pure $(Z, Z)-\mathbf{1 b}$ by powder $\mathrm{X}$-ray diffraction verified that the isomerization proceeded via a crystal-to-crystal reaction process (Fig. 6). Along with a time course the diffractogram pattern became simpler and after $48 \mathrm{~h}$ the diffractogram almost agreed with that of pure $E, E-\mathbf{1 b}$, indicating that the photochemically formed $E$,E-isomer from the $Z, Z$-isomer builds the same crystalline lattice as does the pure $E$,E-isomer.

\section{Figure 6}

Interestingly, 2 showed a different isomerization mode from 1. Either pure $(E, E)-$ or $(E, Z)-2$ gave the photostationary solution containing the mixture of $(E, E)-$ and $(E, Z)-2$ in the ratio of 37:63 upon irradiation for $30 \mathrm{~min}$ in benzene. In contrast, the E,Z-isomer gave the E,E-isomer in 19\% conversion under irradiation for $12 \mathrm{~h}$, while the E,E-isomer did not change at all in the solid state. Such a change in the isomerization mode depending on the phases has been known (25). To explain this unidirectional photoisomerization in the solid-state, it is useful to refer to the phase rebuilding, 
in which the new lattice of the photochemically formed $E, E$-isomer would no longer provide freedom for the reverse process because the E,E-molecules would be strongly interlocked (27).

Although some oligo(phenylene vinylene)s involving more than three stilbene units have been synthesized and their photophysical properties were documented (7-9), their photoisomerization has hardly been investigated except for an example of the poly(phenylene vinylenes) whose all-Z-isomer undergoes a one-way photoisomerization to the all-E-isomer both in solution and in the solid within a thin film (28). We also explored the photochemical behavior of a styrylstilbene 3 , one of oligo(phenylene vinylenes) involving three stilbene units, which was synthesized by the Wittig reaction using a bisphosphonium salt involving the $(E)$-stilbene moiety. Our synthetic procedure gave a mixture of $(E, E, E)-$ and $(E, E, Z)-$ and $(Z, E, Z)-3$, which was successfully separated. The 2-ethylhexyloxy groups attached on the terminal aromatic rings were introduced in order to increase the solubility in organic solvents. Upon irradiation of $(Z, E, Z)-$ and $(E, E, Z)-3$ in benzene, they underwent a one-way photoisomerization to the E,E,E-isomer, but no change was detected for the $E, E, E$-isomer. The time evolution of the reaction progress of $(Z, E, Z)-3$ was monitored by ${ }^{1} \mathrm{H}$ NMR (Fig. 7) and showed that the starting material simply decreased with simple increasing of (E,E,E)-3, the final product, while (E,E,Z)-3 was once formed but gradually declined.

\section{Figure 7}

When the powder of (E,E,Z)-3 was irradiated in the solid-state for $12 \mathrm{~h}$, it also isomerized to the E,E,E-isomer in a $16 \%$ conversion. Unfortunately, $(Z, E, Z)-3$ could not be employed in the solid-state photoisomerization because of the difficulty in solidifying it.

\section{CONCLUSION}

The spectral properties and Z,E-photoisomerization of some 4-styrylstilbenes and 4,4'-distyrylstilbene both in solution and in the solid-state were investigated and some interesting structural effects on both their spectral properties and photoisomerization were observed. In addition, some different photochemical behaviors depending on the reacting phase, in solution or in the solid-state, were also found. In all cases, the photoisomerization in the solid-state proceeded in a one-way manner from $Z$ to $E$ even for the compound that undergoes a mutual photoisomerization in solution.

\section{ACKNOWLEDGEMENTS}

This work was supported by a Grant-in-aid for the $21^{\text {st }}$ Century COE Research and the CLUSTER of the Ministry of Education, Culture, Sports, Science and Technology of Japan. 


\section{REFERENCES}

1. Greenham, N. C., S. C. Moratti, D. D. C. Bradley, R. H. Friend and A. B. Holmes (1993) Efficient light-emitting diodes based on polymers with high electron affinities. Nature. 365, 628-630.

2. Martin, R. E. and F. Diederich (1999) Lineare monodisperse $\pi$-konjugierte Oligomere: mehr als nur Modellverbindungen für Polymere. Angew. Chem. 111, 1440-1469.

3. Liang, T. T., H. Azehara, T. Ishida, W. Mizutani and H. Tokumoto (2004) Synthesis of oligo(para-phenylenevinylene) methyl thiols for self-assembled monolayers on gold surfaces. Synthetic Metals. 140, 139-149.

4. Sokolik, I., Z. Yang, F. E. Karasz and D. C. Morton (1993) Blue-light electroluminescence from p-phenylene vinylene-based copolymers. J. Appl. Phys. 74, 3584-3586.

5. Pfeifer S. and H.-H. Hoerhold (1999) Investigation of poly(arylene vinylene)s, 41 Synthesis of soluble dialkoxy-substituted poly(phenylene alkenyliden)s by applying the Horner-reaction for condensation polymerization. Macromol. Chem. Phys. 200, 1870-1878.

6. Lee, J.-K., R. R. Schrock, D. R. Baigent and R. H. Friend (1995) A new type of blue-light-emitting electroluminescent polymer. Macromolecules. 28, 1966-1971.

7. Xue, C. and F. -T. Luo (2003) Efficient and Rapid Synthesis of Oligo(p-phenylenevinylene) via Iterative coherent Approach. J. Org. Chem. 68, 4417-4421.

8. Detert, H. and V. Schmitt (2004) Quadrupolar donor-acceptor substituted oligo(phenylenevinylene)s-synthesis and solvatochromism of the fluorescence. J. Phys. Org. Chem. 17, 1051-1056.

9. Xiong. H., L. Qin, J. Sun, X. Zhang and J. Shen (2000) Synthesis and self-assembly of rod-coil diblock molecules of oligophenylenevinylene-poly(ethylene oxide). Chem. Lett. 29, 586-587.

10. Sakai, K.-i., T. Tsuzuki, J. Motoyoshiya, M. Inoue, Y. Itoh, M. Ichikawa, T. Fujimoto, I. Yamamoto, T. Koyama and Y. Taniguchi (2003) Relationship between molecular skeleton and stimulated-emission threshold in dilute thin films of linear-chain-structured fluorescent dyes. Chem. Lett. 32, 968-969.

11. Nakatsuji, S., K. Matsuda, Y. Uesugi, K. Nakashima, S. Akiyama, G. Katzer and W. Fabian (1991) Synthesis and absorption/emission spectral properties of styrylstilbene and distyrylanthracene derivatives. J. Chem. Soc. Perkin Trans. 1, 861-867.

12. Motoyoshiya, J., N. Sakai, M. Imai, Y. Yamaguchi, R. Koike, Y. Takaguchi and H. Aoyama (2002) Peroxyoxalate chemiluminescence of $N, N^{\prime}$-bistosyl-1H-4H-quinoxaline-2,3-dione and related compounds. Dependence on electronic nature of fluorophores. J. Org. Chem. 67, 7314-7318. 13. Koike, R., Y. Katayose, A. Ohta, J. Motoyoshiya, Y. Nishii and H. Aoyama (2005) Poly(benzyl ether) dendrimers with strongly fluorescent distyrylbenzene cores as the fluorophores for 
peroxyoxalate chemiluminescence: insulating effect of dendritic structures on fluorescent sites. Tetrahedron, 61, 11020-11026.

14. Armaroli, N., F. Barigelletti, P. Ceroni, J.-F. Eckert, J. -F. Nicoud and J. -F. Nierengarten (2000) Photoinduced energy transfer in a fullerene-oligophenylenevinylene conjugate. Chem Commun. 599-600.

15. Arai, T. and K, Tokumaru (1993) Photochemical one-way adiabatic isomerization of aromatic olefins. Chem. Rev. 93, 23-39.

16. Sandros, K., M. Sundahl, O. Wennerstrom and U. Norinder (1990) Cis-trans photoisomerization of a p-styrylstilbene, a one- and twofold adiabatic process. J. Am. Chem. Soc. 112, 3082-3086.

17. Sundahl, M., O. Wennerstrom, K. Sandros, T. Arai and K. Tokumaru (1990) Triplet state Z/E-isomerization of a p-styrylstilbene: a partly adiabatic process. J. Phys. Chem. 94, 6731-6734.

18. Toda, F. (1995) Solid state organic chemistry: Efficient reactions, remarkable yields, and stereoselectivity. Acc. Chem. Res. 28, 480-486.

19. Tanaka, K and F. Toda (2000) Solvent-free organic synthesis. Chem. Rev. 100, 1025-1074.

20. Natarajan, A., J. T. Mague, K. Venkatesan, T. Arai and V. Ramamurthy (2006) Volume-demanding cis-trans isomerization of 1,2-diaryl olefins in the solid state. J. Org. Chem. 71, 1055-1059.

21. Saltiel, J., T. S. R. Krishna and R. J. Clark (2006) Photoisomerization of cis, cis-1,4-diphenyl-1,3-butadiene in the solid state: the bicycle-pedal mechanism. Phys. Chem. A, 110, 1694-1697.

22. Castells, J., J. Font and A. Virgili (1979) Reaction of dialdehydes with conventional and polymer-supported Wittig reagents. Journal of the Chemical Society, Perkin Transactions 1: Organic and Bio-Organic Chemistry. 1, 1-6.

23. Tewari, Ram S., N. Kumari and P. S. Kendurkar (1976) Generation and reactions of some dimethyl benzylphosphonate carbanions: synthesis of trans-diaryl-substituted ethylenes. Journal of Chemical and Engineering Data. 21(1), 125-131.

24. Xue J. Y., Y. F. Zhang and X. L. Wang (1985) Effect of substituents on the infrared spectra of some 1,4-bis[ $\beta$-(4-substituted phenyl)ethenyl]benzene compounds. Gaodeng Xuexiao Ниахие Xuebao. 6(2), 143-145.

25. Sonoda, Y., Y. Kawanishi, S. Tsuzuki and M. Goto (2005) Crystalline-State Z,E-Photoisomerization of a Series of (Z,E,Z)-1,6-Diphenylhexa-1,3,5-triene 4,4'-Dicarboxylic Acid Dialkyl Esters. Chain Length Effects on the Crystal Structure and Photoreactivity. J. Org. Chem. 70, $9755-9763$.

26. Warshel, A (1976) Bicycle-pedal model for the first step in the vision process. Nature, 260, 679-683. 
27. Kaupp, G. (1995) AFM and STM in photochemistry including photon tunneling. Adv. Photochem. 19, 119-177.

28. Katayama, H., M. Nagao, T. Nishimura, Y. Matsui, K. Umeda, K. Akamatsu, T. Tsuruoka, H. Nawafune and F. Ozawa (2005) Stereocontrolled Synthesis and Optical Properties of All-cis Poly(phenylene vinylenes) (PPVs): A Method for Direct Patterning of PPVs. J. Am. Chem. Soc. 127 (12), $4350-4353$.

Figure Legends

Figure 1: Structures of 4-styrylstilbenes (1a-c), 4,4"-bis( $\beta$-methylstyryl)benzene (2), and 4,4'-distyrylstilbene (3).

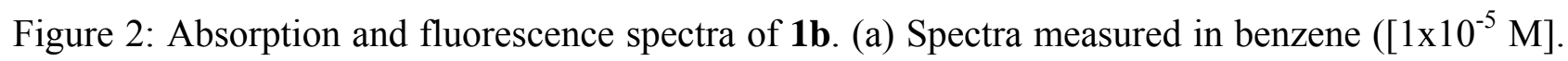
$\left.\lambda_{\mathrm{EX}}: 310 \mathrm{~nm}\right)$. (b) Spectra measured in the solid-state. $\left(\lambda_{\mathrm{EX}}: 390 \mathrm{~nm}\right)$. E,E' shows the spectra of $E, E-1 \mathbf{b}$ generated after irradiation of $Z, Z-1 \mathbf{b}$.

Figure 3: Absorption and fluorescence spectra of 2 and 3. (a) Spectra of 2 measured in benzene $\left(\left[1 \times 10^{-4} \mathrm{M}\right]\right.$ for absorption spectra and $\left[5 \times 10^{-4} \mathrm{M}\right], \lambda_{\mathrm{EX}}: 370 \mathrm{~nm}$ for fluorescence spectra). (b) Spectra of 3 measured in benzene $\left(\left[1 \times 10^{-6} \mathrm{M}\right], \lambda_{\mathrm{EX}}: 395 \mathrm{~nm}\right)$.

Figure 4: Time course of the photoisomerization of E,Z-1a-c to their E,E-isomers in in benzene- $\mathrm{d}_{6}$ (a) and in the solid-state (b).

Figure 5: Time course of photoisomerization of $(Z, Z)-1 \mathbf{b}$ in benzene- $\mathrm{d}_{6}(\mathrm{a})$ and in the solid-state (b). Figure 6: Tracing powder X-ray diffractograms during irradiation of the geometrical mixture of $\mathbf{1 b}$.

Figure 7: Time course of photoisomerization of $(Z, E, Z)-3$ in benzene. 


$$
\longrightarrow-\mathrm{CH}=\mathrm{CH}-\mathrm{CH}=\mathrm{CH}
$$

$$
\begin{aligned}
& \text { 1a, } \mathrm{R}=\mathrm{H} \\
& \text { 1b, } \mathrm{R}=\mathrm{Me} \\
& \text { 1c, } \mathrm{R}=\text { tert }-\mathrm{Bu}
\end{aligned}
$$
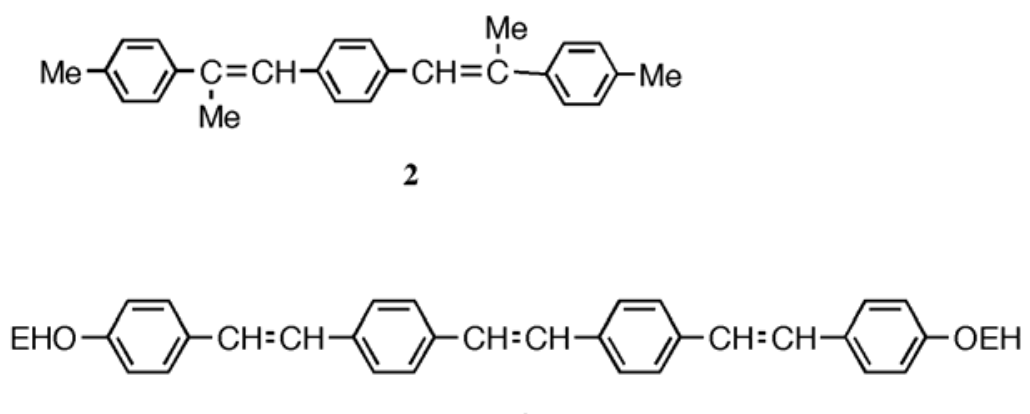

3

$\mathrm{EH}=2$-ethylhexyl

Figure 1
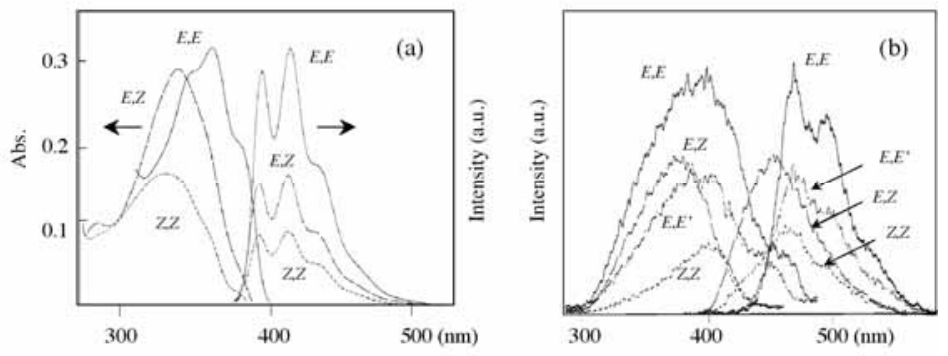

Figure 2
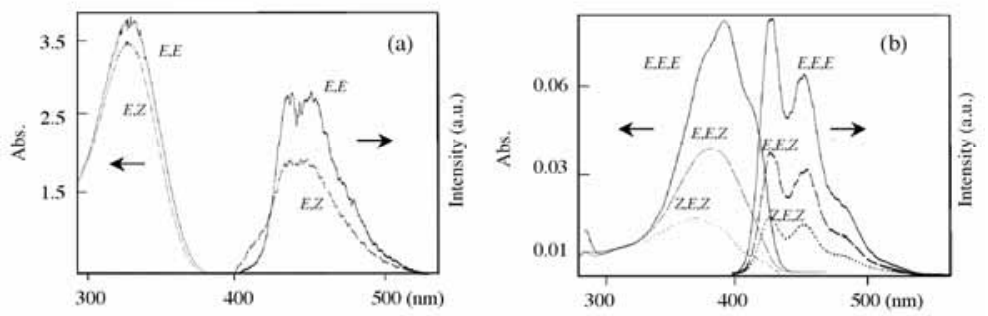

Figure 3 

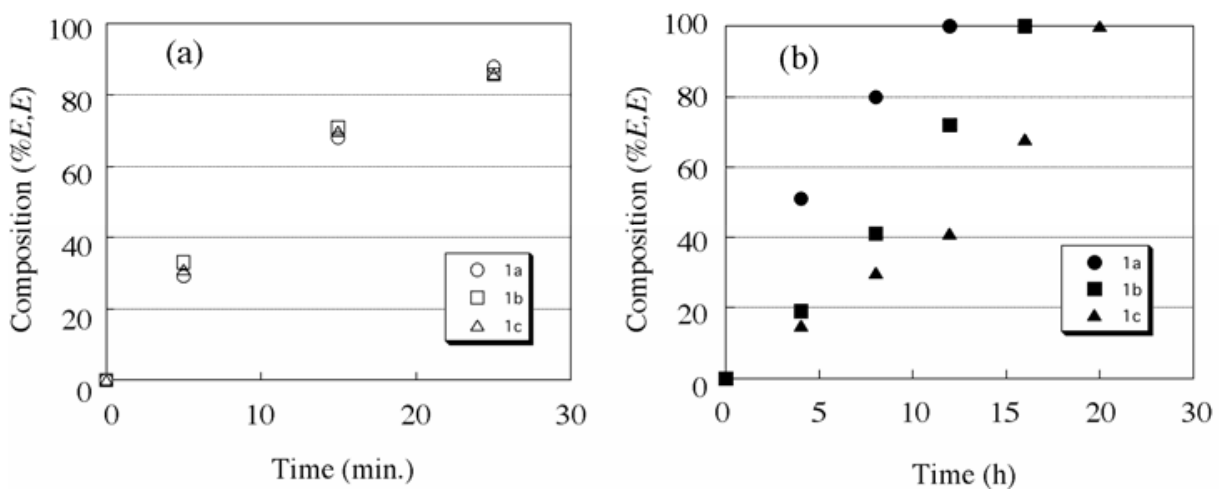

Figure 4
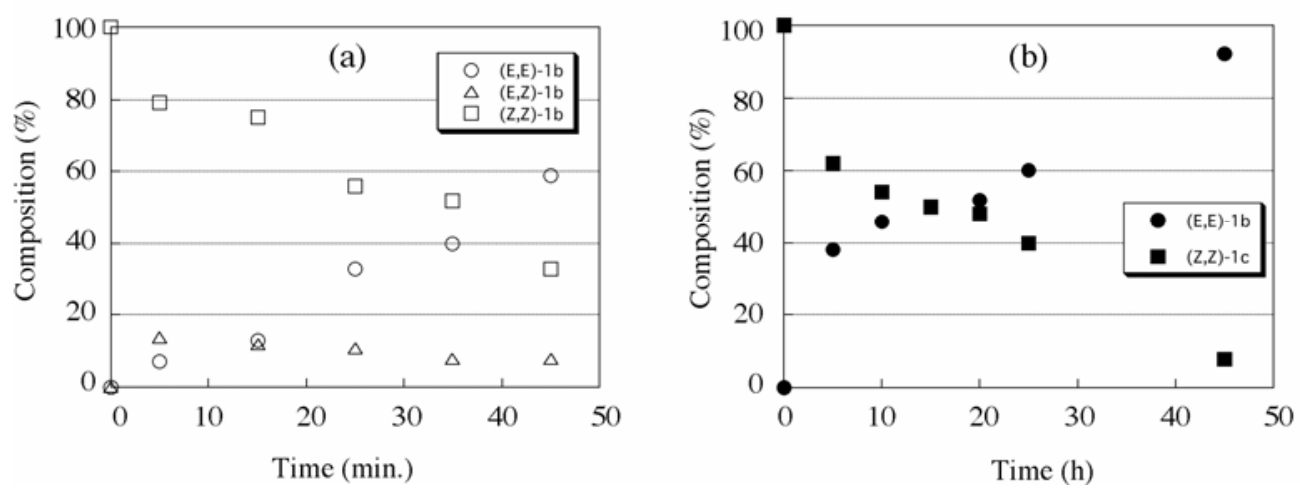

Figure 5 

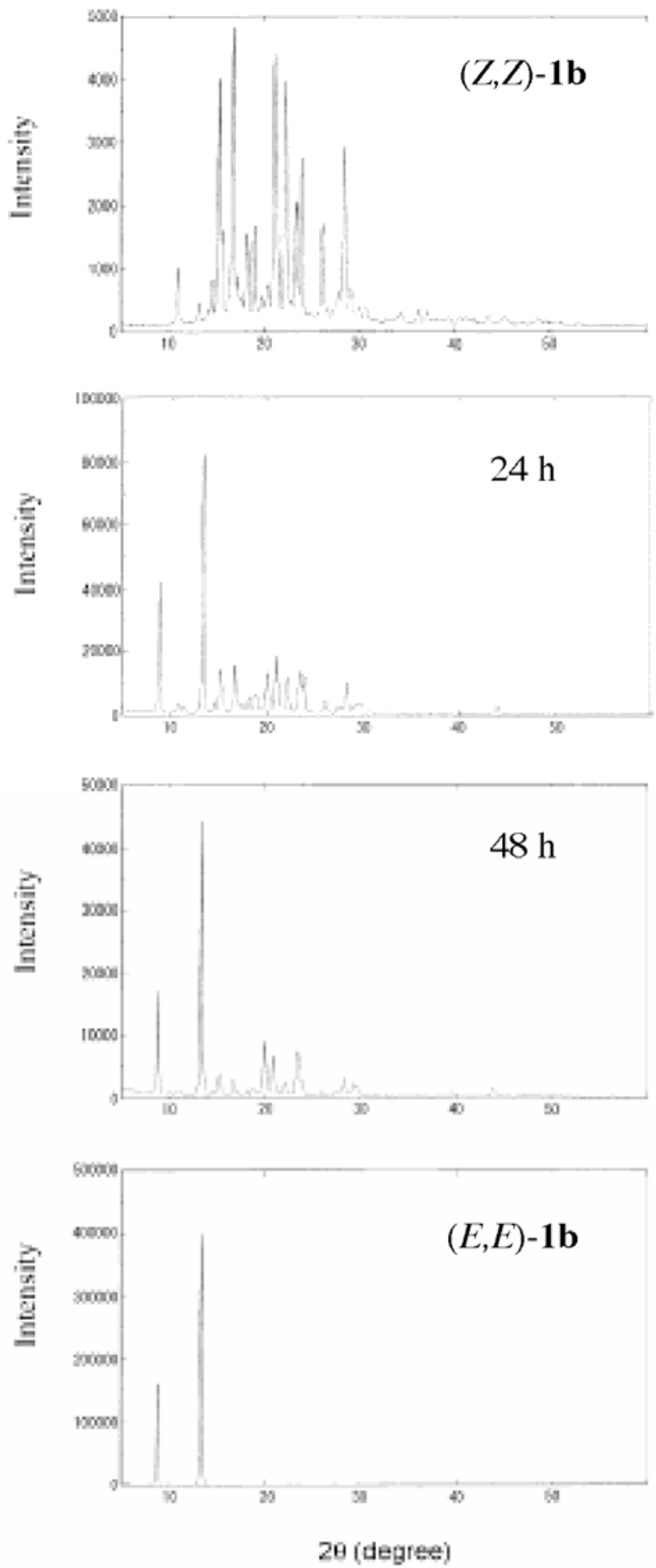

Figure 6 


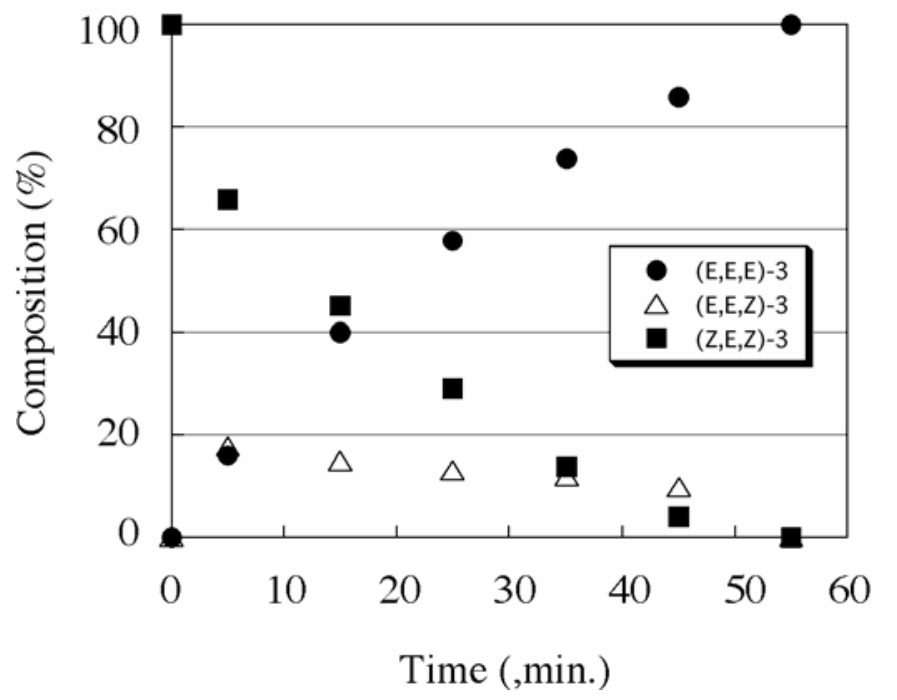

Figure 7 